\title{
Congenital rubella: citation virus or viral cause of type 1 diabetes?
}

\author{
E. A. M. Gale
}

Published online: 19 July 2008

(C) Springer-Verlag 2008

Keywords Congenital rubella syndrome $\cdot$ CRS .

Diabetes mellitus

There is something worse than ignorance, and that's knowing what ain't so

Mark Twain

\section{Mind parasites}

A mind parasite is an invisible assumption that enters the mind unnoticed and occupies the mental dimension more properly reserved for curiosity. Few mind parasites are more deeply embedded in the collective psyche of the diabetes investigator than the vaguely formulated belief that virus infection is a cause of type 1 diabetes. The arguments for this are collectively impressive but individually insubstantial, and the hypothesis hangs together much as a man might attempt to cross a half-frozen river by jumping from one ice floe to the next before the first gives way beneath him. There is indeed an extensive literature to prove that viruses produce diabetes in experimental animals, but no one has ever shown how this relates-other than by

\section{E. A. M. Gale}

Diabetes and Metabolism, Division of Medicine,

University of Bristol,

Bristol, UK

\section{E. A. M. Gale $(\bowtie)$}

Diabetes and Metabolism, Medical School Unit,

Southmead Hospital,

Bristol BS10 5NB, UK

e-mail: Edwin.Gale@bristol.ac.uk analogy - to type 1 diabetes, a condition found only in humans. Much of the human evidence is such that only those who want to believe will do so, but the hypothesis does at least appear to have a secure basis in the congenital rubella syndrome. Many reviews (I will not list them here) repeat the statement that $10-20 \%$ of those afflicted will develop type 1 diabetes, and one report goes up to $40 \%$ [1]. These figures are misleading, but an interesting and much more complex story underlies the beguiling simplicity of this epidemic citation virus.

\section{Rubella}

Rubella, first described in 1814, has clinical features intermediate between those of measles and scarlet fever. In German it was known as Röteln and in English as German measles, a name slowly replaced by the more euphonious rubella. The virus appears in the circulation after an incubation period of 7-9 days, and is shed via the nasopharynx and stools. Clinical onset is preceded by flu-like symptoms, low fever and arthralgia, followed by eruption of small pinkish-red spots, which typically appear on the face 1621 days after exposure before spreading to the rest of the body [2]. The condition sometimes presents without a rash, making bedside diagnosis impossible, and up to $40 \%$ of patients may never realise that they have been affected [3]. The virus disappears from the serum as antibodies appear, some 3 weeks after infection [2]. Although serious consequences such as encephalopathy may result, rubella was long considered the most benign of the common childhood infections. Endemic in many parts of the world, it gave rise to major outbreaks at 10-30 year intervals through much of the twentieth century. Previously unexposed populations 
are at greatest risk, especially children and young adults who are housed together in schools or other institutions.

The conditions for a major outbreak were present in Australia in 1940. Protected by its isolation, it had experienced no major epidemic since 1925 . Young adults were crowded together in military camps and barracks as the country mobilised for war, and the virus swept through the population. One year later, the ophthalmic surgeon Norman Gregg found that infants with an unfamiliar variant of congenital cataract were lining up in his outpatient clinic, and the connection with maternal rubella infection was suggested by two mothers discussing their pregnancies in his waiting room [4]. It took courage for Gregg to draw the inference that a 'harmless' virus could cause a congenital malformation, for the medical wisdom of the day maintained that maternal infection was unable to cross the placenta and considered that inborn abnormalities were predestined from the time of conception. Confirmatory reports soon followed, however, and an ingenious historical analysis showed that epidemics of deafness in the newborn (another consequence of rubella) had occurred at intervals over the previous 50 years, for example, in 1899 following a big outbreak of rubella in 1898 [5].

\section{The congenital rubella syndrome}

Knowledge of this syndrome and its late consequences accumulated over the next 30 years, but much of the information we possess was gained during the course of a pandemic that reached the USA in 1964 and affected an estimated 1.8 million people. One survey found that $10 \%$ of American women pregnant in spring 1964 reported exposure to rubella during the first trimester, and that $0.6 \%$ of these gave birth to a child with the rubella syndrome [6]. This implied that some 20,000 American women might have been infected in pregnancy, and 600 children with possible features of the syndrome were born in New York alone between 1964 and 1966 [7]. In response to this challenge a live attenuated vaccine for rubella was rushed through development and entered clinical use in 1969, since when vaccination has largely eliminated the syndrome in the wealthier countries, although an estimated 100,000 children are still affected each year worldwide [8].

Diagnosis of congenital rubella is based on the classic triad of cataracts, cardiac anomalies and deafness, although the condition is notable for the diversity of clinical disorders it can cause, some of which are listed in the text box. Delayed fetal growth is characteristic, and some $40 \%$ of children weigh less than $2.5 \mathrm{~kg}$ at birth. There is an associated failure of catch-up growth, and in one series, more than $60 \%$ of children failed to reach the 5 th centile for height. Cognitive defects are common in those with growth delay and rare in those with normal growth [9]. Early mortality is high, and 15 of the 78 cases collected by Gregg had died by the time his paper was published in 1941 [10]. Manifestations of the syndrome fall into three groups; transient abnormalities present at birth, persistent abnormalities identifiable at birth or coming to attention in infancy, and late consequences of intrauterine infection. The timing of infection is of critical importance, since the risk of rubellaassociated defects is greatest when maternal infection is acquired in the first 10 weeks of pregnancy, but very low after 18 weeks of gestation. The rubella syndrome was for many years a leading cause of the devastating combination of deafness with blindness. 'It is difficult,' as one victim wrote, 'for most people to imagine living in a world without colour, shape and movement, and where there is no conversation of voices and other sounds' [11]. Contrary to stereotype, learning disability is far from universal, and educational services in my area are organised by a lady who is blind as the consequence of congenital rubella.

\begin{tabular}{|c|}
\hline The congenital rubella syndrome \\
\hline $\begin{array}{l}\text { Transient abnormalities at birth } \\
\text { - Thrombocytopenic purpura } \\
\text { • Bone 'lesions' } \\
\text { • Pneumonitis } \\
\text { - Hepatosplenomegaly }\end{array}$ \\
\hline $\begin{array}{l}\text { Congenital defects } \\
\text { - Sensorineural deafness } \\
\text { - Congenital heart disease } \\
\text { - Cataract, choroidoretinitis } \\
\text { - Growth retardation } \\
\text { - Microcephaly, mental retardation } \\
\text { - Urogenital abnormalities }\end{array}$ \\
\hline $\begin{array}{l}\text { Delayed consequences } \\
\text { • Diabetes } \\
\text { - Thyroid dysfunction } \\
\text { - Behavioural disorders, autism } \\
\text { - Panencephalitis }\end{array}$ \\
\hline
\end{tabular}

The prevalence of the congenital rubella syndrome is less easy to establish than one might imagine. One reason is diagnostic uncertainty, given that viral exposure in pregnancy may be hard to establish, clinical consequences vary according to the timing of infection during gestation, and the syndrome encompasses a spectrum of abnormalities, from the lethal to the relatively trivial. The worst affected do not survive infancy, and ascertainment bias arises when studies of 
the syndrome recruit from sources such as eye clinics or schools for the deaf. Baseline estimates vary accordingly. To give one example, the number of American children born deaf-blind as a consequence of the congenital rubella syndrome in the 1960s ranged somewhere between 739 and 10,000 ! [12]. Furthermore, the striking increase in the number of deaf children born in the USA in 1964-1965 who did not have a diagnosis of maternal rubella suggests that the condition may have been underdiagnosed [13]. Such uncertainties should be borne in mind when considering estimates of the prevalence of diabetes in this condition.

\section{Pathology of the congenital rubella syndrome}

Rubella is an RNA virus with a lipid envelope. The ring effect or 'toga' this produces under the electron microscope caused it to be classed with the Togaviridae, within which it forms a separate genus, Rubivirus. It was first identified and cultured in the early 1960s and exists in a number of similar strains that are serologically indistinguishable; humans are the only known natural host, although experimental rubella can be induced in other species [2]. Fetal lesions have been reported in animals as a consequence of maternal rubella infection, but there is no reliable model of the rubella syndrome. Congenital rubella is characterised by persistent viraemia, and virus can be cultured from the throat, tears and urine of affected children at birth. Viral shedding cannot be detected after 1 year of age in $90 \%$ of cases but may sometimes persist for years. Diagnosis is based upon detection of virus or rubella-specific antibody in early infancy, and standard criteria have been established [14].

Infection of the placental tissue and fetus is almost inevitable when infection occurs within the first 2 months of pregnancy, and $67-85 \%$ of confirmed first trimester infections lead to some form of fetal damage [2]. The importance of timing may relate to the immune competence of the fetus. Virus penetrates almost all tissues and, once established, persists throughout gestation, even though the fetus can mount an effective immunoglobulin response and is additionally protected by maternal IgG following the acute phase of the infection. Neonates with the syndrome have impaired cell-mediated immunity, and an early study from the laboratory of Robert Good found that cells from rubella neonates did not respond to phytohaemagglutinin (PHA), although some recovered normal responses as the viraemia resolved later in infancy [15]. Lymphocytes from healthy individuals acquired the same defect when infected with rubella, and were potentially able to pass the virus to daughter cells without surface transmission. From this, the authors concluded that persistent infection within lymphocytes explains the inability of the fetus to clear itself of infection. There is some evidence of long-term alterations in cell-mediated immunity, and young adults with congenital rubella were reported to have a reduced proportion of $\mathrm{CD}^{+}$(helper) $\mathrm{T}$ cells and an increased proportion of $\mathrm{CD} 8^{+}$ (cytotoxic) $\mathrm{T}$ cells compared with healthy controls and individuals with new-onset type 1 diabetes [16].

There are two main theories as to why rubella induces abnormalities in the fetus [2]. The first is that viral replication impairs proliferation and growth of developing clones of cells at a critical stage of fetal development. Although analysis of aborted fetal material shows that only a small proportion of fetal cells actually harbour virus, cultures derived from these cells grow slowly and produce a growth-inhibiting substance in vitro. The organs of infants with the syndrome are small and contain a reduced number of cells. Viral infection therefore induces general growth delay, with focal consequences in specific tissues that may be more susceptible to infection. The second hypothesis is that direct tissue damage occurs as the result of cell necrosis, as observed in tissues including the eye and vascular endothelium. This leads to immune-mediated changes, including mononuclear infiltrates, in tissues such as the lung and brain. Lesions associated with the syndrome might thus result from a combination of growth delay and inflammation. The effect of congenital rubella upon the pancreas will be considered later.

\section{Congenital rubella and diabetes}

The first instance of diabetes in a child with congenital rubella was mentioned in passing in 1949 [17], but the association between congenital rubella and diabetes came to general recognition via a single case from the Australian 'Gregg cohort' [18], to which four other cases were soon added $[19,20]$.

\section{Case reports}

Twenty published cases were identified by a search of the literature [19-29] and are listed in Table 1. Of these, nine were diagnosed between the ages of 12-48 months; six presented in ketoacidosis, and most required insulin therapy. Two autopsies were performed. One, of a boy aged 14 months who died in ketoacidosis, showed insulitis [27], and the second, of an 11-year-old girl who died in ketoacidosis 7 years after diagnosis, showed atrophic islets considered typical of long-term type 1 diabetes [26].

\section{Case series}

Australia The most detailed longitudinal study is based on long-term follow-up of cases diagnosed by Gregg in New South Wales. A survey of children with hearing difficulties 
Table 1 Reported cases of diabetes in the congenital rubella syndrome

\begin{tabular}{|c|c|c|c|c|c|c|}
\hline Study & $\mathrm{M} / \mathrm{F}$ & Birthweight (g) & $\begin{array}{l}\text { Age at } \\
\text { diagnosis } \\
\text { of diabetes }\end{array}$ & DKA & Insulin-dependent & Other features \\
\hline \multirow[t]{5}{*}{ Forrest et al., 1969 [19] } & $\mathrm{F}$ & & 18 months & + & + & Glaucoma \\
\hline & $\mathrm{F}$ & & 12 years & - & + & Cataract, PDA \\
\hline & M & & 12 years $^{\mathrm{a}}$ & - & + & Deaf, rubella retinopathy \\
\hline & M & & 24 years $^{\mathrm{a}}$ & - & - & Cataracts, pulmonary stenosis \\
\hline & M & & 28 years & - & - & Cataracts \\
\hline \multirow[t]{2}{*}{ Plotkin and Kaye, 1970 [21] } & M & 2,200 & 12 months & - & + & Deaf, PDA \\
\hline & M & & 19 months & + & + & Deaf \\
\hline \multirow[t]{2}{*}{ Johnson and Tudor, 1970 [22] } & M & 2,300 & 3 years & - & + & Deaf, PDA \\
\hline & M & 2,400 & 20 months & - & + & Cataracts, PDA \\
\hline Halvorson, 1977 [23] & M & 2,510 & 7 years & - & + & Deaf, pulmonary stenosis \\
\hline \multirow[t]{2}{*}{ Smithells et al., 1978 [24] } & M & 1,941 & 3.5 years & $?$ & $?$ & Deaf \\
\hline & $\mathrm{F}$ & 1,913 & 2.5 years & $?$ & $?$ & Deaf \\
\hline Floret et al., 1980 [25] & M & 3,050 & 17 years & - & + & Mental retardation, hyperthyroidism \\
\hline Jenson et al., $1980[26]$ & M & & 4 years & + & + & Died in DKA aged 11 years \\
\hline Patterson et al., 1981 [27] & M & & 14 months & + & - & Died in DKA, insulitis, cataract \\
\hline \multirow[t]{2}{*}{ Schopfer et al., 1982 [28] } & $\mathrm{F}$ & 2,270 & 4 years & $-{ }^{\mathrm{b}}$ & + & Deaf, PDA, hypothyroid \\
\hline & $\mathrm{F}$ & 1,900 & 11 years & $-{ }^{\mathrm{b}}$ & - & Deaf, microcephaly, cataracts \\
\hline \multirow[t]{3}{*}{ Takasu et al., 2005 [29] } & $\mathrm{F}$ & & 21 years & + & + & Deaf, cataracts, hypothyroidism \\
\hline & $\mathrm{F}$ & & 13 years & + & + & Deaf, cataracts, mutism \\
\hline & M & & 18 years & - & + & Deaf, cataracts, atrial septal defect \\
\hline
\end{tabular}

DKA, diabetic ketoacidosis; PDA, patent ductus arteriosus

a Member of the 'Gregg cohort'

${ }^{\mathrm{b}}$ Presented in hyperosmolar coma

identified 48 patients born after the outbreak of 1940-1941, and to these were added cases recruited from other sources, including the wedding list of one of the participants [18]. A total of 50 individuals who were willing and able to participate were considered to have a definite diagnosis of congenital rubella; these were examined and studied in more detail. None was known to have diabetes before the initial examination in 1967 , but one 24 -year-old man was found at that time to have undiagnosed diabetes, with a routine blood glucose of $33 \mathrm{mmol} / \mathrm{l}$.

A notice placed in the Medical Journal of Australia in 1968 resulted in a publication describing this patient plus another member of the Gregg cohort, diagnosed by OGTT, together with three reports from other centres [19]. A total of 44 members of the Gregg cohort were subsequently tested by OGTT, in a survey that is widely misquoted as having shown that nine of the $44(20 \%)$ had diabetes. It is therefore important to appreciate that the criteria used to diagnose diabetes were a $1 \mathrm{~h}$ glucose value of $>8.9 \mathrm{mmol} /$ $1(160 \mathrm{mg} / \mathrm{dl})$ or a $2 \mathrm{~h}$ value of $>6.7 \mathrm{mmol} / \mathrm{l}(120 \mathrm{mg} / \mathrm{dl})$. On this basis, five individuals were said to have diabetes. As described above, one had overt diabetes and a second had a diabetic OGTT, but the other three would not be considered to have diabetes by current criteria. Four others had stimulated glucose values below these levels but were deemed to have 'latent diabetes' by criteria that are now obsolete, such as a mismatch of glucose and insulin peaks. The average birthweight of the nine patients was $2.5 \mathrm{~kg}$ (range 1,985-3,435 g). Maternal infection had occurred from 4-16 weeks of gestation in all cases; all were deaf, two had cataracts, two had rubella chorioretinopathy and one had pulmonary stenosis. None of the nine required insulin, although six were treated with oral agents [20].

The members of this cohort were studied again after 50 [30] and 60 [31] years. Seven of the 50 had died by 50 years, including one with a diagnosis of diabetes. Follow-up glucose tolerance tests are not reported, but diabetes is said to have persisted in four out of five of those with abnormal tests; one required insulin and two were on tablets, but none had developed late complications of diabetes. One additional patient developed diabetes in the interim, but no further details were provided. When studied after 60 years, 40 of the originals were still alive, and seven were considered to have type 2 diabetes (none had a diagnosis of type 1). Of these, three were on insulin (two had developed retinopathy and were also found to have high levels of GAD antibodies), one other was on oral medication and the remaining three were on diet alone. The prevalence of type 2 diabetes was $22 \%$ compared with a background prevalence in that age group of $13.1 \%$ [31]. In summary, this cohort study found a high prevalence of type 2 diabetes and two cases suggestive of latent autoimmune 
diabetes in adults (LADA) but no single instance of typical type 1 diabetes.

USA The rubella epidemic of 1964-1966 is estimated to have resulted in some 600 children with the congenital rubella syndrome in New York alone. Of these (and including children born outside this time-frame), 173, and subsequently 242 affected individuals, were identified for study via the Developmental Disabilities Center at $\mathrm{St}$ Luke's-Roosevelt Hospital or the Pediatric Diabetes Clinic at Mount Sinai Hospital [32, 33]. Forty per cent of the children were Hispanic, $25 \%$ black and $30 \%$ of European extraction. The diagnosis of congenital rubella was based on isolation of rubella virus from the newborn (present in $16 \%$ ), serological confirmation by detection of rubellaspecific antibodies in the newborn (41\%) and/or clinical stigmata plus positive serology not obtained in the immediate postnatal period. Given the interest of the investigators, the sample may have included a disproportionate number of children with diabetes. Of these, there were $21 / 173$ in the initial study (mean age 14 years, range 6 months to 24 years) satisfying National Diabetes Data Group criteria (fasting blood glucose $\geq 6.7 \mathrm{mmol} / \mathrm{l} ; 2 \mathrm{~h}$ blood glucose $\geq 10 \mathrm{mmol} / \mathrm{l}$ ), and $16 \mathrm{had}$ experienced ketoacidosis and were on insulin. An expanded group of 242 children was subsequently examined (mean age 17 years); of these, 15 required continuous insulin therapy, one had received insulin intermittently and 14 had abnormal glucose tolerance [33]. Some of the latter, unexpectedly, showed distinctly elevated insulin levels during the OGTT [7], a finding also described but not commented on in an earlier series [20]. The New York studies are remarkable for the very high number of individuals with diabetes, and it is therefore particularly disappointing that individual patient details are summarised but not reported in detail.

A second US study described a cohort of 201 adolescents meeting diagnostic criteria for the congenital rubella syndrome, 152 of whom were born in 1964-1965; all attended institutions for the deaf in Maryland or Virginia. Of these, two had overt diabetes (treatment not specified) and two others were considered to have diabetes on the basis of oral glucose tolerance testing. Overall, 22\% were judged to have abnormal tests, using 1979 National Institutes of Health criteria for children plus some added categories devised by the authors - thus making comparison with other series impossible [34].

UK The National Congenital Rubella Surveillance Programme identified 482 children with confirmed or suspected congenital rubella in 1971-1977; two cases listed in Table 1 come from this registry [24]. These two cases are presumably the same as those described in a long-term follow-up study of
616 UK children exposed to rubella in pregnancy. Since three cases of diabetes were reported in 605 controls, this later survey showed no excess of diabetes [35]. Follow-up data on this cohort are unfortunately not available (P. Tookey, personal communication).

Japan An epidemic outbreak of rubella occurred in 19641965, and 280 individuals with cataracts, sensory deafness and/or heart disease were studied 40 years later. Of these, three had developed diabetes, two presented in diabetic ketoacidosis at the ages of 13 and 18 (Table 1) and required insulin immediately, and another, asymptomatic, individual was picked up by screening and required insulin therapy later in life [29]

Canada The Canadian Deafblind and Rubella Association maintains an active website (http://www.cdbra.ca/) and issues questionnaires from time to time. Its website lists 100 respondents with date of birth ranging back to the 1950s. Of these, four developed diabetes at the ages of $>2$, 9, 14 and 19 years, and another eight are listed with onset between the ages of 21 and 53 years; only seven of the 12 required medication [36].

\section{Immunogenetics of the congenital rubella syndrome}

\section{HLA associations}

The HLA system modulates susceptibility to some viral infections, and it still seems unclear whether this is the case with rubella. Three studies in different populations have suggested that susceptibility is HLA-linked, but the findings are inconsistent [37-39]. In contrast, Rubinstein et al. observed no difference between individuals with congenital rubella and controls [32]. Comparison between 21 affected individuals who also had diabetes and 152 with no diabetes showed HLA DR2 to be present in $25 \%$ of those without, but in none of those with diabetes. HLA DR3 was significantly more frequent in those with diabetes, and the authors propose that exposure to the rubella virus may increase the penetrance of diabetes susceptibility alleles [32].

\section{Autoimmunity and congenital rubella}

The hypothesis that rubella may promote islet autoimmunity is poorly supported by the data, not least because autoantibody testing was in its infancy when most of the studies reported here were conducted. The observations that $\sim 20 \%$ of patients with the syndrome carry islet cell surface antibodies [33], and that $\sim 30 \%$ have insulin autoantibodies 
[7], are uninterpretable owing to the unreliability of the assays used [40]. A more recent analysis of 37 patients, one of whom had diabetes, found no evidence of ICA, IAA, GADA or IA-2A [40], although one of the Japanese patients reported in Table 1 had GADA and IA-2A, and another had GADA alone [29].

While the evidence of islet autoimmunity remains scant, thyroid disease, presumably autoimmune, also appears to be more common in the rubella syndrome [e.g. 25, 28, 29, 40], a finding that has attracted less attention than the association with diabetes, and provides some support for the concept of enhanced autoimmunity.

\section{Congenital rubella and the pancreas}

As described earlier, insulitis was reported in a 14-month-old boy who died in diabetic ketoacidosis [27]. A study of pancreases from five fetuses aborted between 19 and 21 weeks of gestation isolated rubella virus from each but detected no morphological abnormality [41]. In a further study, pancreases from children who died from a range of viral infections, for the most part acquired in the early neonatal period, were studied systematically. The children included 45 with congenital rubella, one of whom developed diabetes at the age of 4 and died in ketoacidosis at the age of 11. The pancreases of 43 were considered normal in appearance, one was thought to have 'slight evidence' of insulitis, and the girl with diabetes had changes consistent with longstanding type 1 disease. In contrast, islet involvement was noted in four out of seven of those infected with Coxsackie B4 virus, 20 of 45 with cytomegalovirus and two of 14 with varicella zoster. This large series demonstrates that a range of overwhelming viral infections can produce morphological changes in the islets, and that congenital rubella is less likely to do so than many other infections [26].

\section{Diabetes and intrauterine viral infection}

Intrauterine or neonatal viral infection has been associated with diabetes in a number of reports, and causal agents include rubella, cytomegalovirus and mumps. A UK study, which began in 1950, identified a total of 3,076 children exposed to viral infection in utero, and these were followed for up to 40 years. The survey included children whose mothers were exposed to rubella in pregnancy, but does not mention how many had features of congenital rubella. Two of 616 children exposed to rubella, and none of 97 exposed to cytomegalovirus developed diabetes, but there were four cases among 128 children exposed to mumps virus in the first trimester of pregnancy, all presenting between the ages of 13 and 21 years [35].
Evidence for a possible association between diabetes and intrauterine infection with viruses other than rubella is very scant. It should, however, be noted that the association between rubella and diabetes might never have come to light if the children had not presented in large numbers at around the same time, and had not required institutional support for easily identifiable afflictions such as deafness and blindness. In all events, this search revealed no further evidence of a link to intrauterine exposure to mumps, and the link to congenital cytomegalovirus is equally tenuous; there is a single report in the literature of a boy who presented with diabetic ketoacidosis at 13 months of age [42]. A Swedish survey compared 76 affected children with 19,483 unaffected children born during the same period; diabetes developed in one of the children with cytomegalovirus and in 38 of the healthy children. This difference did not reach statistical significance, but neither did it exclude a possible association [43]. Equally, there is little support for the notion that intrauterine exposure to enterovirus predisposes to later development of type 1 diabetes [44].

\section{Summary}

As this survey indicates, the congenital rubella syndrome undoubtedly predisposes to diabetes in later life. A high proportion of the reported cases, mostly described in very brief summary (Table 1) presented under the age of 5 years, in children who were for the most part markedly underweight at birth. These were often reported to be in diabetic ketoacidosis at diagnosis, and were invariably treated with insulin. Some adolescents and young adults presented in much the same way, whereas others did not require insulin therapy and some at least had an insulin-resistant form of diabetes. Others had impaired glucose tolerance, although numbers are hard to ascertain owing to the use of differing diagnostic criteria. Those diagnosed later in life have generally not required insulin therapy.

As might be expected, the source material for any retrospective analysis is inadequate. Most reports were published 30-40 years ago, before the distinction between type 1 and type 2 diabetes was well established, and by authors with no special interest in diabetes. The rubella syndrome itself is heterogeneous, and criteria for its diagnosis varied, as did contemporary criteria for the diagnosis of diabetes. None in the Gregg cohort had classic childhood-onset type 1 diabetes, and the UK series identified two of 616 affected children with diabetes as against three of 605 controls [35]. A Japanese series identified three of 280 cases in 40 years of follow-up [29], and one American series identified two of 201 adolescents with 'overt diabetes' [34]. Taken together, these reports suggest that $\sim 1 \%$ of individuals with the rubella syndrome will develop 
diabetes in childhood or adolescence, and that most but not all of these will require insulin.

The striking exception is the New York study, which contains almost half the cases reported in the literature: 21 of 173 (16 on insulin) at a mean age of 14 years [32], and 30 of 242 (15 on continuous insulin) at a mean age of 17 years [33]. Ascertainment bias may have contributed to this very high rate, which is otherwise unexplained. Sadly, these cases are not reported in individual detail and their characterisation in terms of islet autoantibodies is largely outdated. Nor has it proved possible to retrieve sera for further analysis, although there is some faint hope that these may still exist (L. Z. Cooper, personal communication). The absence of HLA DR2 and excess of HLA DR3 in the small sample of 21 cases is, however, consistent with a diagnosis of type 1 diabetes [32].

Why might intrauterine infection with rubella predispose to the subsequent development of diabetes? The first point to make is that these children were all born with an active viraemia, and are likely to have shed virus for at least the first year of their lives. The single case of insulitis reported at the remarkably early age of 14 months [27] might therefore represent an ongoing reaction to active viral infection rather than a delayed autoimmune response. Sporadic cases of early-onset diabetes have been reported with other intrauterine viral infections, but the evidence that rubella has a causal role in the later development of diabetes is much more compelling. One explanation for this might be inhibition of pancreatic development and a reduced beta cell mass, which could be responsible for the high rate of dysglycaemia in those with the syndrome. Beta cell mass expands sevenfold between birth and adult life, and the most rapid increase in beta cell replication occurs in infancy [45]; any interference with this process might therefore predispose to subsequent insulin-deficient diabetes. Low birthweight is a further characteristic of the syndrome, and is known to predispose to the later development of type 2 diabetes.

To conclude: Did the congenital rubella syndrome promote autoimmune diabetes? The issue, as we have seen, is much more complicated than previous reviewers have appreciated. There certainly was an excess of children with ketoacidosis and other features of autoimmune type 1 diabetes. Immunogenetic characterisation of these cases is, however, mostly lacking, although the absence of HLA DR2 and the excess of HLA DR3 in the New York cases is very suggestive. There is no clear evidence that congenital rubella does predispose to subsequent autoimmunity, although the apparent excess of thyroid disease is suggestive. The answer, as Mark Twain might have phrased it, is a definite maybe: there are too many gaps in our knowledge for confident conclusions to be drawn. Sadly for us, but happily for future generations of children, the real answers may never be known.
Acknowledgements I thank S. Hawkins for carrying out the literature review. Many rubella pioneers assisted me in this survey of a vanishing condition. Special thanks to L. Cooper, A. Foulis, M. Honeyman, R. MacEvoy and P. Tookey for their advice, although they are in no way responsible for any erroneous conclusions that I may have drawn.

Duality of interest The author declares that there is no duality of interest associated with this manuscript.

\section{References}

1. Menser MA, Forrest JM, Honeyman MC (1974) Diabetes, HL-A antigens, and congenital rubella. Lancet 1974(2):1508-1509

2. Wolinsky JS, McCarthy M (1995) Rubella. In: Porterfield JS (ed) Handbook of infectious diseases: exotic viral infections. Chapman and Hall, London, pp 19-45

3. O'Donnell N (1996) History of the congenital rubella syndrome. J Vocat Rehabil 6:149-157

4. Burgess MA (1991) Gregg's rubella legacy 1941-1991. Med J Australia 155:355-356

5. Lancaster HO (1951) Deafness as an epidemic disease in Australia. BMJ 2:1429-1432

6. Sever JL, Nelson KB, Gilkeson MR (1965) Rubella epidemic, 1964: effect on 6,000 pregnancies. Am J Dis Child 110:395-407

7. McEvoy RC, Fedun B, Cooper LZ et al (1988) Children at high risk of diabetes mellitus: New York studies of families with diabetes and of children with congenital rubella syndrome. Adv Exp Med Biol 246:221-227

8. Lambert SR (2007) Congenital rubella syndrome: the end is in sight. Br J Ophthalmol 91:1418-1419

9. Chiriboga-Klein S, Oberfield SE, Casullo AM et al (1989) Growth in the congenital rubella syndrome and correlation with clinical manifestations. J Pediatr 115:251-255

10. Gregg NM (1941) Congenital cataract following German measles in the mother. Trans Ophthal Soc Aust 3:35-46

11. Smithdas RJ (1980) Reflections of a deaf-blind adult. Am Ann Deaf 125:1015-1017

12. Lockett T, Rudolph J (1980) Deaf-blind children with maternal rubella: implications for adult services. Am Ann Deaf 125:1002-1006

13. Trybus RJ, Karchmer MA, Kerstetter PP, Hicks W (1980) The demographics of deafness resulting from maternal rubella. Am Ann Deaf 125:977-984

14. Cutts FT, Best J, Siquiera MM, Engstrom K, Robertson SE (1999) Guidelines for surveillance of congenital rubella syndrome and rubella. World Health Organisation, Geneva

15. Olsen GB, Dent PB, Rawls WE et al (1968) Abnormalities of in vitro lymphocyte responses during rubella virus infections. J Exp Med 128:47-68

16. Rabinowe SL, George KL, Loughlin R, Soeldner JS, Eisenbarth GS (1986) Congenital rubella. Monoclonal antibody-defined T cell abnormalities in young adults. Am J Med 81:779-782

17. Hay DR (1949) The relation of maternal rubella to congenital deafness and other abnormalities in New Zealand. New Zealand Med J 48:604-608

18. Menser A, Dods L, Harley JD (1967) A twenty-five-year followup of congenital rubella. Lancet 2:1347-1350

19. Forrest JM, Menser MA, Harley JD (1969) Diabetes mellitus and congenital rubella. Pediatrics 44:445-447

20. Forrest JM, Menser MA, Burgess JA (1971) High frequency of diabetes mellitus in young adults with congenital rubella. Lancet 2:332-334

21. Plotkin SA, Kaye R (1970) Diabetes mellitus and congenital rubella. Pediatrics 46:650-651 
22. Johnson GM, Tudor RB (1970) Diabetes mellitus and congenital rubella infection. Am J Dis Child 120:453-455

23. Halvorson EP (1977) Diabetes mellitus and congenital rubella: report of a case. Mt Sinai J Med 44:566-567

24. Smithells RW, Sheppard S, Marshall WC, Peckham C (1978) Congenital rubella and diabetes mellitus. Lancet 1:439

25. Floret D, Rosenberg D, Hage GN, Monnet P (1980) Hyperthyroidism, diabetes mellitus and the congenital rubella syndrome. Acta Paediatr Scand 69:259-261

26. Jenson AB, Rosenberg HS, Notkins AL (1980) Pancreatic islet-cell damage in children with fatal viral infections. Lancet 2:354-358

27. Patterson K, Chandra RS, Jenson AB (1981) Congenital rubella, insulitis, and diabetes mellitus in an infant. Lancet 1:1048-1049

28. Schopfer K, Matter L, Flueler U, Werder E (1982) Diabetes mellitus, endocrine autoantibodies, and prenatal rubella infection. Lancet 2:159

29. Takasu N, Ikema T, Komiya I, Mimura G (2005) Forty-year observation of 280 Japanese patients with congenital rubella syndrome. Diabetes Care 28:2331-2332

30. McIntosh EDG, Menser MA (1992) A fifty-year follow-up of congenital rubella. Lancet 340:414-415

31. Forrest JM, Turnbull FM, Sholler GF et al (2002) Gregg's congenital rubella patients 60 years later. Med J Aust 177:664-667

32. Rubinstein P, Walker ME, Fedun B, Witt ME, Cooper LZ, Ginsberg-Fellner F (1982) The HLA system in congenital rubella patients with and without diabetes. Diabetes 31:1088-1091

33. Ginsberg-Fellner F, Witt ME, Fedun B et al (1985) Diabetes mellitus and autoimmunity in patients with the congenital rubella syndrome. Rev Infect Dis 7(Suppl 1):S170-S176

34. Shaver KA, Boughman JA, Nance WE (1985) Congenital rubella syndrome and diabetes: a review of epidemiologic, genetic and immunologic factors. Am Ann Deaf 130:526-532
35. Fine PEM, Adelstein AM, Snowman J, Clarkson JA, Evans SM (1985) Long term effects of exposure to viral infections in utero. BMJ 290:509-511

36. Canadian Deafblind and Rubella Association (1998) A survey of late emerging manifestations of congenital rubella in Canada. Available from http://www.cdbra.ca, accessed 30 June 2008

37. Honeyman MC, Dorman DC, Menser MA, Forrest JM, Guinan JJ, Clark P (1975) HL-A antigens in congenital rubella and the role of antigens 1 and 8 in the epidemiology of natural rubella. Tissue Antigens 5:12-18

38. Kato S, Kimura M, Takakura I, Tsuji K, Ueda K (1980) HLAlinked genetic control in natural rubella infection. Tissue Antigens 15:86-89

39. Shaver KA, Boughman JA, Kenyon N, Mohanakumar T, Nance WE (1984) HLA antigens in the congenital rubella syndrome. Dis Markers 2:381-391

40. Viskari H, Paronen J, Keskinen P et al (2003) Humoral $\beta$-cell autoimmunity is rare in patients with the congenital rubella syndrome. Clin Exp Immunol 133:378-383

41. De Prins F, Van Assche FA, Desmyter J, De Groote G, Gepts W (1978) Congenital rubella and diabetes mellitus. Lancet 2:439-440

42. Ward KP, Galloway WH, Auchterlonie IA (1979) Congenital cytomegalovirus infection and diabetes. Lancet 1:497

43. Ivarsson SA, Linberg B, Nilsson KO, Ahlfors K, Svanberg L (1993) The prevalence of type 1 diabetes at follow-up of Swedish infants congenitally infected with cytomegalovirus. Diabet Med 10:521-523

44. Gale EAM, Atkinson M (2004) A piece of nucleic acid surrounded by controversy: coxsackievirus and the causes of type 1 diabetes. Diabet Med 21:503-506

45. Meier JJ, Butler AE, Saisho Y et al (2008) Beta-cell replication is the primary mechanism subserving the postnatal expansion of beta cell mass in humans. Diabetes 57:1584-1594 